\title{
ASSOCIATION BETWEEN PUBERTAL STATUS AND BODY FAT PERCENTAGE AMONG MALAY ADOLESCENTS IN KUALA NERUS, TERENGGANU
}

\author{
NUR AFIFAH MOHD KHAIR and BEE SUAN WEE \\ School of Nutrition and Dietetics, Faculty of Health Sciences, \\ Universiti Sultan Zainal Abidin, 21300 Kuala Nerus, Terengganu, Malaysia \\ "E-mail: beesuan@unisza.edu.my
}

Accepted 19 October 2021, Published online 30 November 2021

\begin{abstract}
Body composition is defined as the proportion of fat (FM) and fat-free mass (FFM) in our body. It is an important aspect of both individual's and populations' health. The rising prevalence of obesity among adolescents has highlighted the significance of body fat measurement and the factors that influence it. Therefore, this study aims to measure the body fat percentage $(\mathrm{BF} \%)$ by using bioelectrical impedance analysis (BIA) and to observe its association with pubertal status among Malay adolescents in Kuala Nerus, Terengganu. Adolescents from 10 to 16 years old were the subject of this crosssectional study. Weight, height, and waist circumference were measured anthropometrically, and body composition was determined using Bodystat Quadscan 4000 through BIA procedures. Questionnaires consist of socio-demographic characteristics and Tanner staging for the determination of pubertal status. A total of 310 students participated in this study (female, $n=165$, male $n=145$ ). The percentage of overweight and obese adolescents in Kuala Nerus was $12.9 \%$ and $10.6 \%$, respectively. The difference in BF\% between genders was significant $(p<0.001)$, with pubertal girls having a greater $\mathrm{BF} \%$ than boys $(28.05 \pm 7.31 \%$ vs $17.20 \pm 8.43 \%)$. Between pubertal status and $\mathrm{BF} \%$, there was a significant difference $(\mathrm{p}<0.05)$. However, there was no significant association between $\mathrm{BF} \%$ and pubertal status. Gender and pubertal status have an impact on the $\mathrm{BF} \%$. Thus, pubertal status should be considered when measuring $\mathrm{BF} \%$ because it varies by individual and gender.
\end{abstract}

Key words: Adolescent, body fat percentage, obesity, pubertal status

\section{INTRODUCTION}

Human body composition study focuses on the masses of different body components and their distribution. For instance, the quantitative relations among body components, the in-vivo measurements of body components, and the quantitative changes in these components are associated with multiple intrinsic and extrinsic factors (Zhu \& Wang, 2011). The ability to make these measurements such as using in vivo procedure (Bioelectrical impedance analysis (BIA), ultrasound imaging, air displacement plethysmography, dual-energy X-ray absorptiometry, dilution technique, magnetic resonance imaging, and magnetic resonance spectroscopy) or anthropometric measurement has progressed quickly, with advantages both to the scientist researchers and population studied (Wells \& Fewtress, 2006). Body

* To whom correspondence should be addressed. composition measurements are closely related to clinical medicine, sports science, geriatric prescription, and nutrition (Verlaan et al., 2017). As a result, it is essential to observe $\mathrm{C} 1$ the compositional nature and deviations in different health and disease states to enhance human wellbeing.

Body composition measurement is typically used to focus on the changes in body components with the risk of diseases such as AIDS, cardiovascular risk factors, renal and various other diseases (Jahnsen et al., 2003). Assessment of body composition also provides information for the effectiveness of a certain treatment (Saladino, 2014) including assessing athletes' desirable body weight according to their type of sports (Jackson \& Pollock, 2016)

Anthropometric assessments are the most widely used technique for evaluating body composition. Anthropometric estimations portray weight, level of 
fatness, size, and shape. However, as weight is gain or loss, the association power of anthropometric measures and indices changes. (Frisard et al., 2005). Thus, standardized anthropometric methods are fundamental for clinical and research study comparisons.

One of the issues, why the measurement of body fat percentage $(\mathrm{BF} \%)$ is becoming concerned, is because of the increasing number of obese people. The prevalence of obesity in Malaysia is epidemic. For both genders, the prevalence of overweight ranges from 4.5 to 69.0 percent, and the prevalence of obesity ranges from 3.5 to 16.0 percent (Majid, 2015). Since the prevalence of obesity-related comorbidities, such as type 2 diabetes, has also increased, it is apparent that monitoring and treating obesity and its comorbidities is a major concern. Thus, it is important to assess the body composition changes in precision and the target tissue. However, our ability to assess the tissue composition of the body, specifically body fatness, limits this ability. For a variety of reasons, there is no universally recommended method for measuring or quantifying obesity, and present methods are restricted in their utility in obese people. As previously stated, existing approaches are effective for measuring both normal weight and overweight individuals, but they both have significant shortcomings. Depending on the subject population and particular characteristics required for interpretation, the clinician or researcher must choose the optimal approach for evaluating body composition according to the usefulness and limitations of available methods. (Duren et al., 2008).

Another issue of interest was the variations in body fat distribution that may impact all populations, such as differences between men and women, with aging, pubertal status, ethnicity, and sleep pattern (Institute of Medicine (US) Subcommittee on Military Weight Management, 2004). These differences provide different fat-free mass or fat mass predictive equations for every country because of our differences in body structure or frame. This is why the study of body composition is still being conducted now to find accurate results on why it causes a certain situation or disease to occur.

Despite many studies that have been conducted globally, the newest data on BF\% among Malaysian school children, particularly in a suburban state like Terengganu, is limited (Ahmad et al., 2017). There is a lack of study related to body composition assessment related to the pubertal status being done in Kuala Terengganu, so limited data on obesity of individuals living in this state especially among adolescents; a transitional phase of growth between childhood and adulthood aged between 10 and 19 years (WHO, 2019). Puberty represents a period during the development of a gradual transition from childhood to adulthood. Secondary sexual deve- lopment, cognitive changes, increased growth velocity, and drastic changes in body composition are all caused by endocrine changes throughout puberty. Adult body composition and risk for adult morbidities such as obesity, cardiovascular disease, and dyslipidemia may be predicted by pubertal body composition (Loomba-Albrecht \& Styne, 2009).

Hence, due to this controversy, this study was conducted to determine the association between pubertal status with body fat percentage among Malay adolescents in Kuala Nerus, Terengganu. Plus, most of the studies concerning this finding were conducted on subjects age range between 20 to 60 years old. Thus, this is why adolescents (school children aged 10 to 16 years old) were chosen as the studied subjects in the present study. The result of this study can provide the mean $\mathrm{BF} \%$ and indirectly provide the estimation of the prevalence of obesity in Terengganu. This research can also identify the association between pubertal status and BF\% among adolescents.

\section{MATERIALS AND METHODS}

\section{Study setting}

This study was a cross-sectional study and was conducted in Kuala Terengganu, Terengganu. There were 137 registered schools all over Kuala Terengganu including both primary and secondary schools. Kuala Nerus district was chosen as the specific place where the study was taken over. Kuala Nerus is one of the districts in Kuala Terengganu that is governed by Kuala Terengganu City Council (MBKT). This district consists of a few major towns and villages which are Gong Badak, Seberang Takir, Batu Rakit, Batu Enam, and Kuala Nerus Town (Capital). The schools were selected randomly as listed by the Terengganu State Education Department which compromises adolescents aged between 10 to 16 years old.

\section{Study sample}

In this study, single-stage cluster sampling was used specifically. A basic random sample of clusters is chosen in single-stage cluster sampling, and data were collected from every unit in the sampled clusters (William et al., 2019). The participants were eligible if they were (a) Malay, (b) age between 10 to 16 years old for both genders, (c) healthy and not diagnosed with any diseases. The sample size was calculated using the single mean formula (Equation 1) with a total of 310 students required for this study (Novotny et al., 2006).

$$
n=\left(\frac{Z_{1-\frac{a}{2}} * \sigma}{\Delta}\right)-\text { Equation } 1
$$




\section{Ethical consideration}

The consent of the participants was ensured with their verbally informed of their willingness to participate in this study. A formal meeting with all of the school principals for the selected secondary schools was held and the details of how the study is organized were informed in detail including the objectives and the procedures accompanied with the permission letters to conduct this study from UniSZA, Ministry of Education (MOE) (KPM 600-3/ 2/3-eras (4430)), and Terengganu State Education Department (JPNT) (P.T. 06030-35(22)). The ethical approval of this study was obtained from the UniSZA Health Research Ethics Committee (UHREC/ 628-2(92)). Written informed consent was obtained from parents before the data collection.

\section{Procedures}

Self-administered questionnaires on sociodemographic information were distributed by the teachers to the adolescents. For adolescents in primary school, they were asked to give this questionnaire to their parents so that they could answer it for them. This questionnaire consists of the adolescent's gender, date of birth, and health status. Apart from that, the information about the adolescent's parents was also included which comprised questions asking about their educational level, type of employment, household income, and medical history of their family.

During the data collection, the student's height, weight, hip, and waist circumference were taken with standard protocols. Their BF\% was measured by using the bioelectrical impedance analysis (BIA) technique through Bodystat 4000 equipment and to measure this accurately, the adolescents were informed to at least fast for $4 \mathrm{hr}$ before the measurement.

As for the measurement of pubertal status, the participants were given a questionnaire consisting of images of 5 stages of pubic hair (both sexes), genitals (male), and breast (female). They were asked to rate at which stage they are. The questionnaire also included the question, where the participants need to tick when they start their menstruation either early (below 12 years old), middle (12 to 15 years old), and late (above 15 years old) (Tanner, 1962).

Next, self-assessment of secondary sexual characteristics was used to measure maturational development, as established by Tanner (1962), with levels of maturation ranging from one to five, with one being pre-pubertal and five being posted pubertal and deemed complete maturity. Comparisons with drawings depicting the five stages of development were used to determine the self-assessment of the maturational stage. The participants were asked to assess their private parts and rate their stage (1-5) of pubertal status according to the images visualized in the questionnaire. Tanner staging was validated using the approach established by Matsudo and Matsudo (1994), which categorized adolescents in B1 and G1 as prepubertal, B2-B4, and G2-G4 as pubertal, and B5 and G5 as post-pubertal.

\section{Statistical analysis}

IBM SPSS Statistic 20 was used to enter and analyze all of the data. The socio-demographic features of the subjects were summarised using descriptive statistics. Based on their normality distribution, numerical data were presented as mean (SD) or median (IQR). Categorical data were reported as frequency (percentage). In addition, The MannWhitney U test was employed to compare the mean $\mathrm{BF} \%$ between genders. Further, the association between pubertal status and body fat percentage among Malay adolescents in Kuala Nerus, Terengganu was determined using Fisher's Exact test (significant at $p<0.05$ ).

\section{RESULTS}

A total of 310 primary and secondary school adolescents from the district of Kuala Nerus, Terengganu, aged between 10 years old to 16 years old participated in this study.

Table 1 shows the mean \pm SD for the age in this study was $12.9 \pm 0.1$ years old in which most of them are 13 to 14 years old $(n=146)$. There are more female adolescents $(n=165)$ who participated in this study than male adolescents $(n=145)$.

As for the parent's educational status and paternal smoking status, the majority of the fathers and mothers had completed secondary education (69\% vs $70.6 \%)$, about $40 \%$ of the fathers are smokers, the other $60 \%$ stated non-smokers. Aside from that, most of the participants who joined in this study came from B40 ( $<$ RM 3860) group for household income, which is $48.1 \%$. Only $14.2 \%$ were in the category of T20 (>RM 8319). The categorization of household income was based on the Department of Statistics Malaysia (2017).

Table 2 shows the anthropometric and body composition measurements of primary and secondary school children. The mean BMI of female was $21.16 \pm 0.38 \mathrm{~kg} / \mathrm{m}^{2}$, meanwhile for male was $18.76 \pm 0.35$ $\mathrm{kg} / \mathrm{m}^{2}$. Both genders have the highest number of participants in the category of normal for BMI-forage which are $34.5 \%$ and $32.6 \%$ respectively. Next, as for $\mathrm{BF} \%$ between gender, female adolescents had $28.05 \pm 0.56 \%$ of body fat, whereas for a male adolescent was $16.95 \pm 0.69 \%$. Females had the higher mean for weight, height, fat mass, waist circumference, hip circumference, and waist-to-hip ratio when compared to males $(49.07 \mathrm{~kg}$ vs $43.42 \mathrm{~kg}$, 
Table 1. Distribution and socio-demographic characteristics of School Children

\begin{tabular}{|c|c|c|c|c|c|}
\hline \multirow[b]{2}{*}{ Variables } & \multirow{2}{*}{$\begin{array}{l}\text { Total } \\
n(\%)\end{array}$} & \multirow{2}{*}{$\begin{array}{l}\text { Boys } \\
n(\%)\end{array}$} & \multirow{2}{*}{$\begin{array}{l}\text { Girls } \\
n(\%)\end{array}$} & \multicolumn{2}{|c|}{$95 \% \mathrm{Cl}$} \\
\hline & & & & $\begin{array}{l}\text { Lower } \\
\text { Bound }\end{array}$ & $\begin{array}{l}\text { Upper } \\
\text { Bound }\end{array}$ \\
\hline \multicolumn{6}{|l|}{ School $(n=310)$} \\
\hline SMK Kompleks Seberang Takir & $95(30.6)$ & $41(13.2)$ & $54(17.4)$ & 25.5 & 36.1 \\
\hline SK Kompleks Seberang Takir & $96(31.0)$ & $55(17.7)$ & $41(13.2)$ & 25.8 & 36.1 \\
\hline SMK Kompleks Gong Badak & $96(31.0)$ & $49(15.8)$ & $47(15.2)$ & 26.1 & 36.5 \\
\hline SMKA Dato' Haji Abbas & $23(7.4)$ & $0(0)$ & $23(7.4)$ & 4.5 & 10.6 \\
\hline \multicolumn{6}{|l|}{ Age Group $(n=310)$} \\
\hline $10-11$ & $96(31.0)$ & $55(17.7)$ & $41(13.2)$ & 25.8 & 35.8 \\
\hline $13-14$ & $146(47.1)$ & $74(23.9)$ & $72(23.2)$ & 41.6 & 53.6 \\
\hline $15-16$ & $68(21.9)$ & $16(5.2)$ & $52(16.8)$ & 17.4 & 26.8 \\
\hline \multicolumn{6}{|l|}{ Paternal's Education Status $(n=310)$} \\
\hline No formal education & - & & & & \\
\hline Complete primary education & $7(2.3)$ & & & & \\
\hline Complete secondary education & $214(69.0)$ & & & & \\
\hline Complete matriculation & $4(1.3)$ & & & & \\
\hline Complete college/university & $85(27.4)$ & & & & \\
\hline No formal education & - & & & & \\
\hline \multicolumn{6}{|c|}{ Maternal's Education Status ( $n=310)$} \\
\hline No formal education & - & & & & \\
\hline Complete primary education & $3(1.0)$ & & & & \\
\hline Complete secondary education & $219(70.6)$ & & & & \\
\hline Complete matriculation & $10(3.2)$ & & & & \\
\hline Complete college/university & $78(25.2)$ & & & & \\
\hline \multicolumn{6}{|l|}{ Paternal's Smoking Status $(n=310)$} \\
\hline Smoker & $124(40.0)$ & & & & \\
\hline Non-smoker & $186(60.0)$ & & & & \\
\hline \multicolumn{6}{|l|}{ Household Income ${ }^{a}(n=310)$} \\
\hline <RM 3860 (B40) & $149(48.1)$ & & & & \\
\hline RM 3860 - RM 8319 (M40) & $117(37.7)$ & & & & \\
\hline >RM 8319 (T20) & $44(14.2)$ & & & & \\
\hline
\end{tabular}

aBased on the Department of Statistics Malaysia (2016).

$151.48 \mathrm{~cm}$ vs $150.54 \mathrm{~cm}, 14.66 \mathrm{~kg}$ vs $7.99 \mathrm{~kg}, 74.05 \mathrm{~cm}$ vs $69.37 \mathrm{~cm}, 88.25 \mathrm{~cm}$ vs $80.04 \mathrm{~cm}$ and 0.48 vs 0.46 , respectively). However male adolescents $(35.47 \mathrm{~kg})$ had a higher mean for fat-free mass than female adolescents $(34.55 \mathrm{~kg})$. The total of $\mathrm{BF} \%$ for overfat and obese for both genders were $25.2 \%$ and $3.9 \%$ respectively.

Table 3 shows the median difference of $\mathrm{BF} \%$ between male and female adolescents using the Mann-Whitney U test. Females had a higher median of $\mathrm{BF} \%$ compared to males which were $27.80(9.55) \%$ and $14.70(10.70) \%$ respectively $(p<0.001)$. This result indicated that female adolescents had more $\mathrm{BF} \%$ than male adolescents (Kirchengast, 2017).

Furthermore, Table 4 shows the median differences of $\mathrm{BF} \%$ between pubertal stages (prepubertal, pubertal, and post-pubertal) using the Kruskal-Wallis test. The pubertal stage had the highest median followed by the pre-pubertal stage and post-pubertal stage, which were 24.30 (15.90)\%, $14.35(8.30) \%$, and $10.75(11.13) \%$ respectively. The result using this test showed that there was a significant $(p<0.05)$ difference between tanner staging and $\mathrm{BF} \%(\mathrm{U}=9.168, P=0.010)$. This indicated that individuals who were in the pubertal stage had higher BF\% compared with individuals who were in pre-or post-pubertal stages.

Lastly, Table 5 shows the association between pubertal stages and BF\% groups using Fisher's exact test. $2.6 \%$ of individuals who were not in the pubertal stage were in the normal BF\% category but none of them was overfat or obese. Meanwhile, individuals in the pubertal stage were mostly in the normal category which was $67.4 \%$, only $30.0 \%$ were in the overfat or obese category. Nevertheless, the result showed that there was no association between pubertal stages and the BF\% category. 
Table 2. Anthropometric and body composition measurement among school children

\begin{tabular}{|c|c|c|c|c|c|}
\hline Variables & $\begin{array}{c}\text { Total } \\
n=310 \\
n(\%)\end{array}$ & $\begin{array}{c}\text { Female } \\
n=165 \\
n(\%)\end{array}$ & Mean $\pm S D$ & $\begin{array}{c}\text { Male } \\
n=145 \\
n(\%)\end{array}$ & Mean $\pm S D$ \\
\hline \multicolumn{6}{|l|}{ Body Mass Index ${ }^{b}$ (BMI) } \\
\hline Severe thinnes $(<-3 S D)$ & $9(2.9)$ & $2(0.6)$ & & $7(2.3)$ & \\
\hline Thinnes $(<-2 S D-\leq-3 S D)$ & $21(6.8)$ & $5(1.6)$ & & $16(5.2)$ & \\
\hline Normal $(\leq-2 S D-\leq+1 S D)$ & $208(67.1)$ & $107(34.5)$ & $21.16 \pm 0.38$ & $101(32.6)$ & $18.76 \pm 0.35$ \\
\hline Overweight (>+1SD- $\leq+2 S \mathrm{SD})$ & 39 (12.9) & $22(7.1)$ & & $17(5.5)$ & \\
\hline Obese $(>+2 S D)$ & $33(10.6)$ & $29(9.4)$ & & $4(1.3)$ & \\
\hline \multicolumn{6}{|l|}{ Body Fat Percentage ${ }^{c}(B F \%)$} \\
\hline Normal & $220(71)$ & $111(35.8)$ & & $109(35.2)$ & \\
\hline Overfat & $78(25.2)$ & $49(15.8)$ & $28.05 \pm 0.56$ & $29(9.4)$ & $16.95 \pm 0.69$ \\
\hline Obese & $12(3.9)$ & $5(1.6)$ & & $7(2.3)$ & \\
\hline Weight,kg & & & $49.07 \pm 14.66$ & & $43.42 \pm 14.46$ \\
\hline Height, cm & & & $151.48 \pm 9.79$ & & $150.54 \pm 14.71$ \\
\hline Fat mass, kg & & & $14.66 \pm 7.64$ & & $7.99 \pm 6.08$ \\
\hline Fat-free mass, kg & & & $34.55 \pm 7.65$ & & $35.47 \pm 10.38$ \\
\hline Waist Circumference, $\mathrm{cm}$ & & & $74.05 \pm 11.42$ & & $69.37 \pm 11.67$ \\
\hline Hip Circumference, $\mathrm{cm}$ & & & $88.25 \pm 11.10$ & & $80.04 \pm 10.82$ \\
\hline \multicolumn{6}{|l|}{ Waist-to-Height ratio (WHtR) ${ }^{d}$} \\
\hline Low risk $(<0.5)$ & $213(68.7)$ & $105(33.9)$ & $0.48 \pm 0.07$ & $108(34.8)$ & $0.46 \pm 0.07$ \\
\hline High risk $(\geq 0.5)$ & 97 (31.3) & $60(19.4)$ & & 37 (11.9) & \\
\hline
\end{tabular}

bBMI-for-Age Z-scores, WHO (2007).

cBased on Heo et al. (2012); Taylor et al. (2002).

dBased on McCarthy \& Ashwell, (2006).

Table 3. Median difference of body fat percentage (BF\%) between female and male adolescents

\begin{tabular}{|c|c|c|c|c|}
\hline \multirow[b]{2}{*}{ Variables } & \multicolumn{2}{|c|}{ Gender } & \multirow[b]{2}{*}{ U Statistic } & \multirow[b]{2}{*}{$P$ Value $f$} \\
\hline & $\begin{array}{c}\text { Female } \\
(n=165) \\
\text { Median (IQR) }\end{array}$ & $\begin{array}{c}\text { Male } \\
(n=145) \\
\text { Median (IQR) }\end{array}$ & & \\
\hline $\mathrm{BF} \%$ & $27.80(9.55)$ & $14.70(10.70)$ & 4008.50 & $P=0.000$ \\
\hline
\end{tabular}

e Mann-Whitney $\mathrm{U}$ test, significant at $p<0.001$.

Table 4. Median differences of body fat percentage (BF\%) between pubertal stages

\begin{tabular}{|c|c|c|c|c|c|}
\hline \multirow[b]{2}{*}{ Variables } & \multicolumn{3}{|c|}{ Pubertal Stage (Tanner staging, average) } & \multirow[b]{2}{*}{ U statistics } & \multirow[b]{2}{*}{$P$ value } \\
\hline & $\begin{array}{c}\text { Pre-pubertal stage } \\
(n=4) \\
\text { Median (IQR) }\end{array}$ & $\begin{array}{c}\text { Pubertal stage } \\
(n=302) \\
\text { Median (IQR) }\end{array}$ & $\begin{array}{c}\text { Post-pubertal stage } \\
(n=4) \\
\text { Median (IQR) }\end{array}$ & & \\
\hline BF\% & 14.35 (8.30) & $24.30(15.90)$ & $10.75(11.13)$ & 9.168 & 0.010 \\
\hline
\end{tabular}

${ }^{\mathrm{f}}$ Kruskal-Wallis Test, significant at $p<0.05$.

g Tanner (1962). 
Table 5. Association between pubertal stages and body fat percentage (BF\%) groups

\begin{tabular}{lcccc}
\hline & \multicolumn{2}{c}{ Tanner stage, $n(\%)$} & & \\
\cline { 2 - 3 } Variables & $\begin{array}{c}\text { Not in pubertal stage } \\
\text { (stage 1 and 5) }\end{array}$ & $\begin{array}{c}\text { In pubertal stage } \\
\text { (stage 2 to 4) }\end{array}$ & $\chi^{2}$ & $P$ Value $^{\mathrm{k}}$ \\
\hline BF\% & & & & \\
$\quad$ Normal & $(2.6)$ & $209(67.4)$ & 3.519 & 0.111 \\
$\quad$ Overfat/Obese & 0 & $93(30.0)$ & & \\
\hline
\end{tabular}

h Fisher's exact test, significant at $p<0.05$.

\section{DISCUSSION}

This study was a cross-sectional study where all participants were chosen randomly from one primary school and three secondary schools around Kuala Nerus, Terengganu with an age range between 10 to 16 years old excluding year 6 (UPSR) and form 5 (SPM) students. A total of 310 students were recruited in this study comprising 165 female adolescents and 145 male adolescents.

Based on the result shown in Table 1, the prevalence of obesity among Kuala Nerus adolescents was $10.6 \%$. It was observed that female adolescents had a higher obesity prevalence which was $9.4 \%$ compared to male adolescents which was $1.3 \%$ with the BMI-for-age indicator. The prevalence of obesity found in this study was slightly lower than that found by Ahmad et al. in 2017 among children (aged 10 to 17) in Terengganu which was 12\%. Plus, they discovered that boys had a higher prevalence of obesity than girls in their research. This indicates that the prevalence of obesity is decreasing from the year 2017 to 2019 (Ahmad et al., 2017).

Several factors, including physiological changes and lifestyle variations between sexes at this age, can explain this (Wang, 2002). Girls at this age may have a much greater BMI than boys due to rapid development and physical changes related to sexual maturity and puberty. Girls often have their puberty growth spurt two years earlier than boys (Allen, 2013). Plus, in secondary schools, girls tend to participate in less physical activity, such as sports, than boys (Slater \& Tiggemann, 2011).

Next, Table 3 showed that there was a significant difference in $\mathrm{BF} \%$ between female adolescents and male adolescents $(p<0.001)$. In this study, female adolescents had a higher median $\mathrm{BF} \%$ which was $27.80(9.55) \%$ compared to male adolescents which were $14.70(10.70) \%$. Kirchengast's (2010) findings support the results of the current study, as she discovered that girls and boys of all ages differed considerably in terms of fat mass and lean mass $(p<0.001)$. The results of the present study were also slightly similar to those of Foo et al. (2013) where they too found significant differences in body fatness in Malay adolescent males and females $(p<0.001)$.

The reason is maybe males and females have major differences (age group 10-13 \& 14-16) in tissue distribution. Males have more fat-free mass and bone mineral mass than females because they have larger arm muscles, larger and stronger bones, less limb fat, and more central distribution of fat. Meanwhile, females tend to have higher fat mass when compared to males (Karastergiou et al., 2012). Additionally, men store more fat in the visceral (abdominal) depot, whereas women store more fat in the gluteal-femoral area (Blaak, 2001).

On the other hand, as for the differences and association between pubertal stages and $\mathrm{BF} \%$, the result showed that there was a significant difference between tanner stages and $\mathrm{BF} \%(p<0.05)$. Almost all of the adolescents, $302(97.4 \%)$ were in the pubertal stage, the other $8(2.6 \%)$ participants were in the prepubertal and post-pubertal stage. This is logical because most adolescents commonly are in the pubertal stage for their growth development. The composition and distribution of the body vary between sexes. During puberty, hormones cause substantial sexual dimorphism, with boys gaining more muscle mass than fat mass and girls gaining more fat mass as a natural component of their sexual and reproductive development (McCarthy \& Ashwell, 2006).

However, in this study, it was found that there was no association between different pubertal status stages and the $\mathrm{BF} \%$ group $(p=0.111)$ based on Table 5 . This could be due to no participants in the nonpubertal stage were found to be overweight or obese thus causing no association obtained. In a 2013 article, Cintra et al. emphasized that it is critical to analyze the pubertal stage because the age at which each stage is attained varies greatly. Cut-off values that just account for chronological age are insufficient for measuring obesity in adolescents since sexual maturation has a substantial impact on body composition.

There were some limitations in conducting this study. First, the tanner staging questionnaire was a self-assessment questionnaire, so, it is prone to error 
and bias. Students might feel embarrassed to answer the question about their private parts thus making them feel reluctant to answer the questionnaire. Other than that, there is a very limited sample of individuals who were not in a pubertal stage that are overweight or obese. Thus, the result especially, to see the differences or association is hard to analyze because of the inadequate sample. Other tests also are limited to be analyzed due to this problem.

In conclusion, this study found that the prevalence of obesity among primary and secondary adolescents in Kuala Nerus, Terengganu was 10.6\% which was lower when compared with NHMS 2019 (14.8\%) and Ahmad et al. (2017) (12\%) for the children below age 18 years old. Girls had a higher $\mathrm{BF} \%$ median than boys in this research. This could be possible because boys have more arm muscle mass, larger and stronger bones, less limb fat, and a more central fat distribution than girls. Meanwhile, girls have considerably more total adipose tissue than boys (Karastergiou et al., 2012). It was seen that in this study adolescent who was in pubertal stage had higher $\mathrm{BF} \%$ than adolescents who were in pre/post-pubertal stage. The $\mathrm{BF} \%$ of girls in the pubertal stage was discovered to be higher than that of boys in the pubertal stage. These findings suggest that pubertal status should be included when measuring $\mathrm{BF} \%$ because it varies by individuals and gender. To prevent the increasing number of obesity among adolescents, lifestyle modification, especially through a balanced diet and physical activity, as well as positive health knowledge and behavior change, should be introduced as soon as possible. While obesity is already a major public health concern, underweight adolescents should be considered equally to avoid long-term health implications. One of the most important ways to address this issue is to provide nutritious meals to the students at school. It is also sufficient to notify the responsible parties, who must then implement and establish appropriate intervention measures to address the underlying health issues. Nonetheless, a longitudinal prospective study examining the relative risk that these adolescents face should be conducted.

\section{ACKNOWLEDGEMENTS}

This project was partially funded by the UniSZA DPU Research Grant Scheme (UniSZA/2017/DPU/43). The authors would like to thank all students who willingly participated in this study and gave great cooperation during this study. We are also grateful to the school principals, all teachers, and the Ministry of Education for giving us permission and cooperation to conduct this study.

\section{REFERENCES}

Ahmad, A., Zulaily, N., Shahril, M.R., Abdul Manan, N.S., Fadzli, S.A, Wafa, S.W, Amin, R.M. \& Ahmed, A. 2017. Obesity determinants among Malaysian schoolchildren: What is new? Proceedings of the Nutrition Society, 76(OCE4): E213.

Ahmad, A., Zulaily, N., Abdul Manan, N.S., Shahril M.R., Wafa, S.W., Amin, R.M., Abdullah, E.F. \& Ahmed, A. 2017. Body weight status of school adolescents in Terengganu, Malaysia: a population baseline study. BMC Public Health, 17: 9 .

Allen, E. 2013. Growth and development, ages 13 to 17-what parents need to know. advocates for youth. [WWW Document] URL www.advocates foryouth.org/parents/156-parents (accessed 02.24.2021).

Blaak, E. 2001. Gender differences in fat metabolism. Clinical Nutrition and Metabolic Care, 4(6): 499-502.

Cintra, I.P., Ferrari, G.L., Soares, A.C., Passos, M.A., Fisberg, M. \& Vitalle, M.S. 2013. Body fat percentiles of Brazilian adolescents according to age and sexual maturation: a cross-sectional study. BMC Pediatric, 13: 96.

Department of Statistics Malaysia. Report on Household Expenditure Survey 2017 [WWW Document]. URL https://www.dosm.gov.my/v1/ index. (accessed 02.24.2021).

Duren, D.L., Sherwood, R.J., Czerwinski, S.A., Lee, M., Choh, A.C., Siervogel, R.M. \& Cameron, C.W. 2008. Body composition methods: Comparisons and interpretation. Journal of Diabetes Science and Technology, 2(6): 11391146.

Frisard, M.I., Greenway, F.L. \& Delany, J.P. 2005. Comparison of methods to assess body composition changes during a period of weight loss. Obesity Research, 13(5): 845-854.

Foo, L.H., Teo, P.S., Abdullah, N.F., Aziz, M.E. \& Hills, A. 2013. Relationship between anthropometric and dual energy X-ray absorptiometry measures to assess total and regional adiposity in Malaysian adolescents. Asia Pacific Journal of Clinical Nutrition, 22(3): 348-356.

Heo, M., Faith, M.S., Pietrobelli, A. \& Heymsfield, S.B. 2012. Percentage of body fat cutoffs by sex, age, and race-ethinicity in the US adult population from NHANES 1999-2004. American Journal of Clinical Nutrition, 95: 594-602.

Institute of Medicine (US) Subcommittee on Military Weight Management. 2004. Weight Management: State of the Science and Opportunities for Military Programs. National Academies Press, Washington. 
Jackson, A.S. \& Pollock, M.L. 2016. Practical assessment of body composition. The Physician and Sport Medicine, 13(5): 76-90.

Jahnsen, J., Falch, J.A., Mownckel, P. \& Aadland, E. 2003. Body composition in patients with inflammatory bowel disease: A population based study. American Journal of Gastroenterology, 9: $1556-1562$.

Karastergiou, K., Smith, S.R., Greenberg, A.S. \& Fried, S.K. 2012. Sex differences in human adipose tissues - the biology of pear shape. Biology of Sex Differences, 3(1): 13.

Kirchengast, S. 2017. Gender differences in body composition from childhood to old age: An evolutionary point of view. Journal of Life Sciences, 2(1): 1-10.

Loomba-Albrecht, L.A. \& Styne, D.M. 2009. Effect of puberty on body composition. Current Opinion in Endocrinology, Diabetes and Obesity, 16(1): 10-15.

Majid, H.A., Abidin, M.S., Zamani, A., Su, T.T. \& Hairi, F.M. 2015. Systematic review on the prevalence of overweight and obesity among adolescents in malaysia 1990-2014. EC Nutrition, 26: $475-482$.

Matsudo, S.M.M. \& Matsudo, V.K.R. 1994. Selfassessment and physical assessment of sexual maturation in Brazilian boys and girls: concordance and reproducibility. American Journal of Human Biology, 6: 451-455.

McCarthy, H.D. \& Ashwell, M. 2006. A study of central fatness using waist-to-height ratios in UK children and adolescents over two decades supports the simple message - keep your waist circumference to less than half your height. International Journal of Obesity, 30: 988-992.

Novotny, R., Daida, Y.G., Grove, J.S., Marchand, L.L., \& Vijayadeva, V. 2006. Asian adolescents have a higher trunk: Peripheral fat ratio than whites. The Journal of Nutritition, 136(3): 642-647.

Saladino, C.F. 2014. The efficacy of Bioelectrical Impedance Analysis (BIA) in monitoring body composition changes during treatment of restrictive eating disorder patients. Journal of Eating Disorder, 2(1): 34.
Slater, A. \& Tiggemann, M. 2011. Gender differences in adolescent sport participation, teasing, selfobjectification and body image concerns. Journal of Adolescence, 34: 455-463.

Tanner, J.M. 1962. Growth at Adolescence. Blackwell, Oxford.

Taylor, R.W., Jones, I.E., Williams, S.M. \& Goulding, A. 2002. Body fat percentages measured by dualenergy X-ray absorptiometry corresponding to recently recommended body mass index cut offs for overweight and obesity in children and adolescents aged 3-18 years. The American Journal of Clinical Nutrition, 76(6): 1416-1421.

Verlaan, S., Aspray, T.J, Bauer, J.M, Cederholm, T., Hemsworth, J., Hill, T.R., McPhee, J.S., Piasecki, M., Seal, C., Sieber, C.C., Ter, Borg. S., Wijers, S.L. \& Brandt, K. 2017. Nutritional status, body composition, and quality of life in communitydwelling and non-sacrcopenic older adults: A case-control study. Clinical Nutrition, 36(1): 267-274.

Wang, Y. 2002. Is obesity associated with early sexual maturation? A comparison of the association in american boys versus girls. Pediatrics, 110: 903-10.

Wells, J.C. \& Fewtrell, M.S. 2006. Measuring body composition. Archives of Diseases in Childhood, 97(7): 612-617.

WHO. 2019. Adolescents health [WWW Document]. URL http:// www.who.int/westernpacific/healthtopics/adolescent-health (accessed 3.28.21).

Williams, T.A., Sweeney, D.J., Anderson, D.R., Gaur, A., Higgins, J., Lotha, G. \& Sampaolo, M. 2019. Sample survey methods [WWW Document]. URL https://www.britannica.com/science/ statistics/Sample-survey-methods (accessed 3.28.21).

Zhu, S. \& Wang, Z. 2011. Body composition: Clinical implications and biological diversities. International Journal of Obesity, 35: 51-53. 